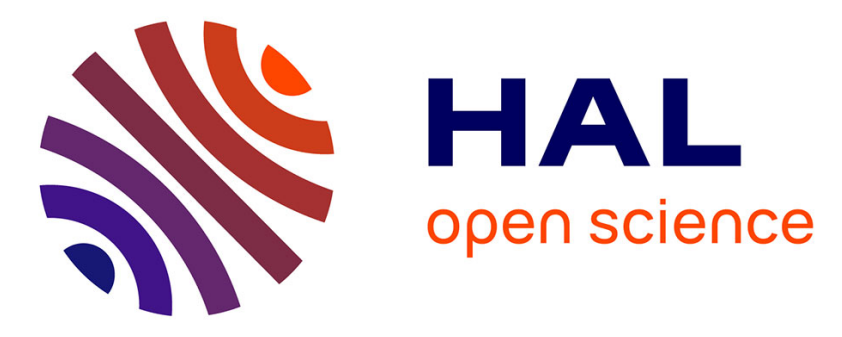

\title{
Infrared laser stimulation of retinal and vestibular neurons
}

Fabrice Bardin, Jean-Michel Bec, Emmanuelle S Albert, Christian P. Hamel, Gérard Dupeyron, Christian Chabbert, Isabelle Marc, Michel Dumas

\section{- To cite this version:}

Fabrice Bardin, Jean-Michel Bec, Emmanuelle S Albert, Christian P. Hamel, Gérard Dupeyron, et al.. Infrared laser stimulation of retinal and vestibular neurons. Photonic Therapeutics and Diagnostics, pp.78834Y, 2011, 10.1117/12.874260 . hal-02496687

\section{HAL Id: hal-02496687 \\ https://hal.science/hal-02496687}

Submitted on 3 Mar 2020

HAL is a multi-disciplinary open access archive for the deposit and dissemination of scientific research documents, whether they are published or not. The documents may come from teaching and research institutions in France or abroad, or from public or private research centers.
L'archive ouverte pluridisciplinaire HAL, est destinée au dépôt et à la diffusion de documents scientifiques de niveau recherche, publiés ou non, émanant des établissements d'enseignement et de recherche français ou étrangers, des laboratoires publics ou privés. 


\title{
Infrared laser stimulation of retinal and vestibular neurons
}

\author{
Fabrice Bardin*a,b ${ }^{\text {a Jean-Michel Bec }}{ }^{\mathrm{b}}$, Emmanuelle S. Albert ${ }^{\mathrm{c}}$, Christian Hamel $^{\mathrm{c}}$, Gérard Dupeyron ${ }^{\mathrm{d}}$, \\ Christian Chabbert ${ }^{\mathrm{c}}$, Isabelle Marc ${ }^{\mathrm{e}}$, Michel Dumas ${ }^{\mathrm{b}}$ \\ ${ }^{a}$ Univ. de Nîmes, Place Gabriel Péri, Nîmes, France 30000; \\ ${ }^{\mathrm{b}}$ Institut d'Electronique du Sud, CNRS UMR5214, Montpellier, France 34095; \\ ${ }^{\mathrm{c}}$ Institut des Neurosciences de Montpellier, INSERM Unité 583, Montpellier, France 34091; \\ ${ }^{\mathrm{d}}$ CHU Nîmes, Place du Pr R Debré, Nîmes, France 30029; \\ ${ }^{\mathrm{e}}$ Ecole des Mines d'Ales, Nîmes, France 30035
}

\begin{abstract}
The study of laser-neuron interaction has gained interest over the last few years not only for understanding of fundamental mechanisms but also for medical applications such as prosthesis because of the non-invasive characteristic of the laser stimulation. Several authors have shown that near infrared lasers are able to stimulate neurons. It is suggested that a thermal gradient induced by the absorption of the laser radiation on cells is the primary effect but the exact mechanism remains unclear. We show in this work that infrared laser radiations provide a possible way for stimulating retinal and vestibular ganglion cells. We describe relevant physical characteristics allowing safe and reproducible neuron stimulations by single infrared pulses. Calcium fluorescence imaging and electrophysiological recordings have been used to measure ionic exchanges at the neuron membrane. The stimulation system is based on a pulsed laser diode beam of a few $\mathrm{mW}$. Effects of three different wavelengths (from 1470 to $1875 \mathrm{~nm}$ ) and stimulation durations have been investigated. Variations of the stimulation energy thresholds suggest that the main physical parameter is the water optical absorption. Measurements of the temperature at the cell membrane show that a constant temperature rise is required to stimulate neurons, suggesting a photothermal process.
\end{abstract}

Keywords: Laser-tissue interaction, neuron, retinal ganglion cell, vestibular ganglion cell

\section{INTRODUCTION}

The study of laser-neuron interaction has gained interest over the last few years not only for understanding of fundamental mechanisms but also for medical applications such as prosthesis because of the non-invasive characteristic of the laser stimulation. Several authors have shown that near infrared lasers are able to stimulate nerves [1,2] or neurons $[3,4]$. It is suggested that a thermal gradient induced by the absorption of the laser radiation on cells is the primary effect but the exact mechanism remains unclear.

We describe in this work physical characteristics allowing safe and reproducible stimulation of retinal and vestibular primary neuron by single infrared laser pulses. Two techniques have been used to measure ionic exchanges through the neuron membrane: calcium fluorescence imaging and electrophysiological recordings (by whole cell path clamp method). The stimulation system is based on a pulsed laser diode beam of a few mW launched into a multimode optical fiber placed at a few micrometers away from the cells. Effects of three different wavelengths (1470, 1535 and 1875 nm), position and stimulation duration have been investigated. Values of stimulation energy thresholds show that the neuronal stimulation clearly depends on the water optical absorption coefficient. Finally measurements of the temperature rise at the neuron membrane level are presented.

*fabrice.bardin@unimes.fr; phone 0033466279578; fax 0033466279554; unimes.fr 


\section{MATERIALS AND METHODS}

\subsection{Preparation of cultured ganglion cells}

All experiments were made in vitro using cultures of Vestibular Ganglion Cells (VGC) from rats or Retina Ganglion Cells (RGC) from C57BL/6J mice and were carried out in accordance with the European Communities Council Directive 86/609/EEC.

Vestibular ganglion neurons were prepared as described in [5].

Post natal (P2) C57BL/6J mice were decapitated. Retinas were removed and transferred in Phosphate Buffered Saline (PBS) medium at $37^{\circ} \mathrm{C}$ and then enzymatically dissociated in PBS containing papain (33 U/mL) for $30 \mathrm{~min}$ at $37^{\circ} \mathrm{C}$. They were then mechanically and gently triturated in PBS containing $1 \%$ ovomucoid and DNase (100 U/mL). Dissociated RGC were incubated for $15 \mathrm{~min}$ at $4{ }^{\circ} \mathrm{C}$ with mouse anti-mouse CD90 Thy1.2 antibodies conjugated to microbeads in PBS with $0.2 \%$ Bovine Serum Albumin (BSA). After washing, cells were eluted using a plunger. Approximately 20000 cells per $\mathrm{cm}^{2}$ of purified RGC were cultured onto glass bottom dishes coated with poly-D-Lysine $\left(20 \mu \mathrm{g} / \mathrm{mL}\right.$ for $2 \mathrm{~h}$ at $\left.37^{\circ} \mathrm{C}\right)$. Eventually, cells were incubated in supplemented Neurobasal at $37^{\circ} \mathrm{C}$ in a $5 \% \mathrm{CO} 2$ humidified atmosphere.

\subsection{Patch-clamp recording and calcium fluorescence imaging}

Whole-cell patch-clamp recordings were performed in current clamp mode on an inverted microscope. Currents were amplified using an Axopatch 200B amplifier, low-pass filtered at $5 \mathrm{kHz}$ through a built-in 8-pole Bessel filter, and sampled at $250 \mathrm{kHz}$ with a multifunctional data acquisition card (NI PCI 6221, National Instruments, Austin, TX). Data acquisition of the patch-clamp measurements were synchronized with the laser stimulation using a homemade National Instrument's LabVIEW program. Pipette series resistance and capacitance were compensated using the built-in circuitry of the amplifier, and the liquid junction potential between the pipette and the bath was zeroed before seal formation. Pipettes were fabricated from borosilicate glass with an initial access resistance less than 6 M $\Omega$. All voltages were defined as membrane potentials with respect to extracellular solutions.

Calcium fluorescence imaging tests were realized with an upright microscope equipped with a 60X objective. Picosecond pulses produced by a Ti:sapphire laser (Tsunami, Spectra-Physics, Mountain View, CA) operated at 760 nm were used for the fluorescence excitation of Fluo3-AM (Exciton, Dayton, OH) a specific calcium fluorescent probe. Fluorescence signals were recorded by photomultiplier tubes, digitized into 8-bit values and analyzed on specific software (Bio-Rad Laboratories, Hercules, CA). Before calcium fluorescence imaging tests, cells were incubated at $37^{\circ} \mathrm{C}$ during 30 minutes in Fluo3-AM.

\subsection{Laser stimulation}

Figure 1 provides a schematic view of the experimental set-up used by both measurement techniques. Three pigtailed laser diodes (Sheaumann laser Inc., Marlborough, MA) emitting in the near infrared at $1875 \mathrm{~nm}, 1535 \mathrm{~nm}$ and $1470 \mathrm{~nm}$ were used. They were mounted on an air cooling block and operated at room temperature. A multimode fiber of $105 \mu \mathrm{m}$ core diameter (0.22 NA) was cleaved and polished to expose the fiber core on one end whereas the other end of the fiber was connected via a SMA connector to the fiber output of the laser diodes. The optical fiber was mounted on an $\mathrm{x}-\mathrm{y}-\mathrm{z}$ translator attached to a micromanipulator to control the fine position. A visible light was also coupled to the fiber for alignment to the target area, before switching to the infrared laser.

All laser stimulation parameters (radiant exposure, pulse duration, repetition rate) were totally controlled through a LabVIEW program. This program controls the laser diode driver (LDX 3232, ILX Ligthwave, MT) by a computer data acquisition and control board (DAQ PCI 6221, National Instruments, TX). It provides the recording of signals at a sampling rate of $25 \mathrm{kHz}$ and the generation of a single pulse with a duration as short as $10 \mu \mathrm{s}$ at the driver maximum output current of $4 \mathrm{~A}$. At the bare fiber output, a maximum output power (obtained at $3.5 \mathrm{~A}$ ) of $230 \mathrm{~mW}$ for the $1875 \mathrm{~nm}$ laser, $410 \mathrm{~mW}$ for the $1535 \mathrm{~nm}$ laser and $430 \mathrm{~mW}$ for the $1470 \mathrm{~nm}$ laser was measured by a powermeter. 


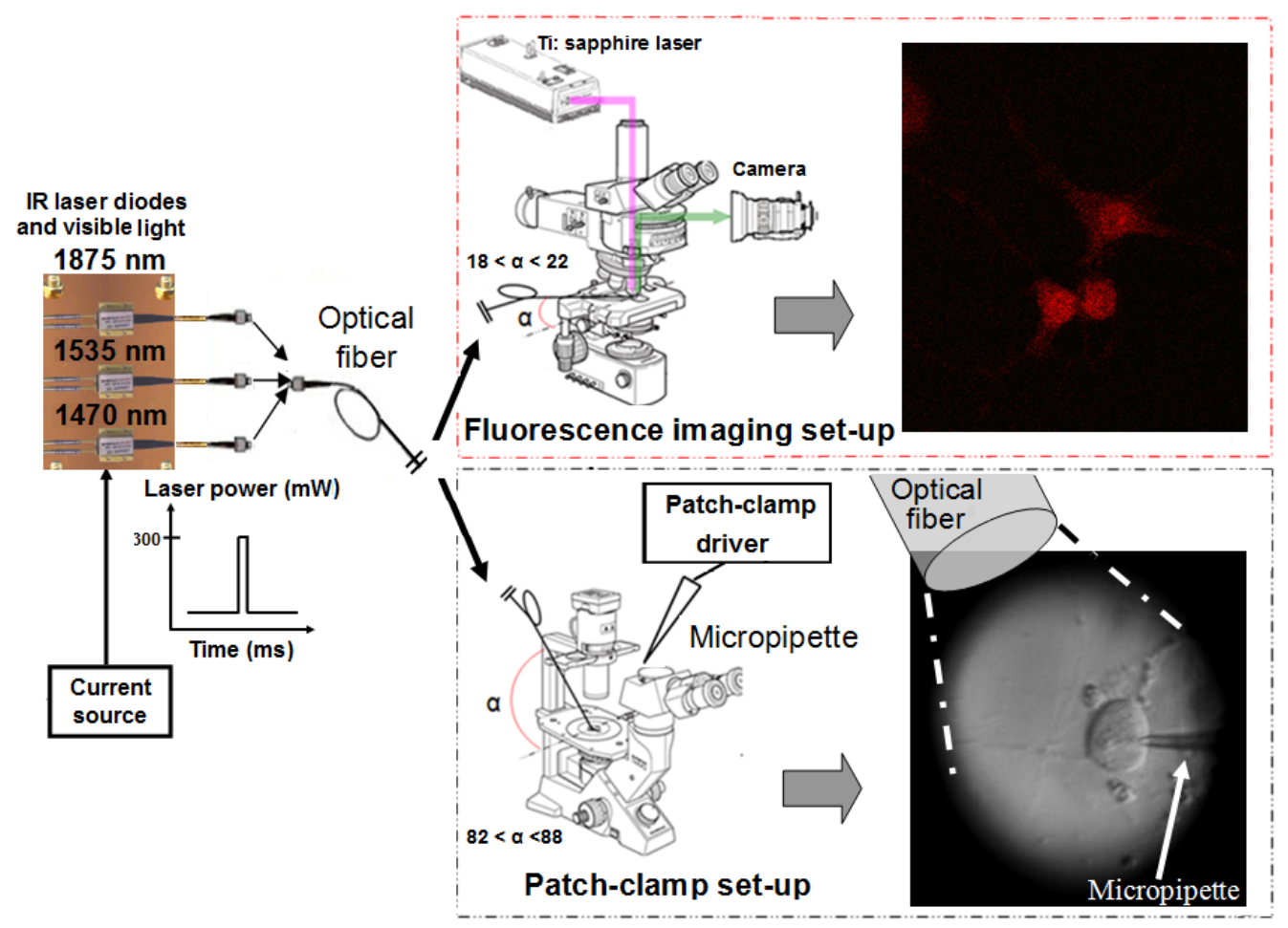

Figure 1. Schematic illustration of the experimental setups.

\subsection{Temperature measurement at cellular level}

Several authors have shown that the local temperature could be monitored by irradiating the tip of an open patch pipette $[3,6]$. The local temperature change induces a resistance variation of the electrode tip. Calibrations were performed with the bath solution preheated beforehand (around $45-50^{\circ} \mathrm{C}$ ) and passively cooled until $24^{\circ} \mathrm{C}$ (Figure 2). The temperature control of the bath solution was simultaneously monitored using an immersed thermometer. A square voltage command pulse of $5 \mathrm{mV}$ was applied to generate a current through the open pipette. Figure 2 shows a quasi linear evolution of current function of the temperature in the range $25-50^{\circ} \mathrm{C}$ as described in [6].

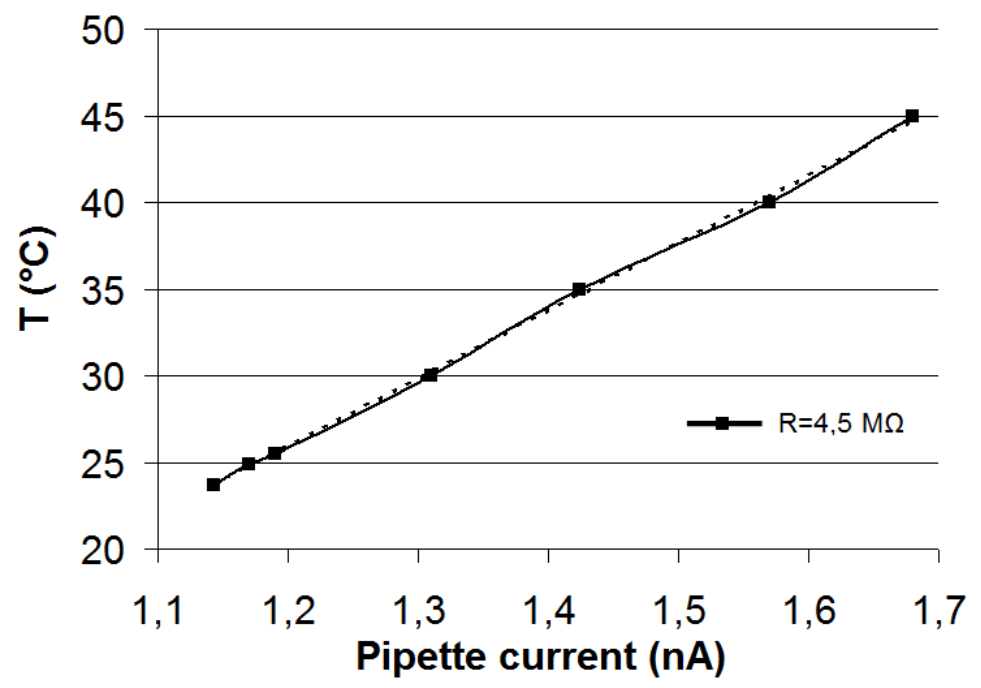

Figure 2. Experimental calibration of the pipette current function of the bath temperature. 


\section{RESULTS}

Successful laser stimulation of neurons were validated for transient, reproducible and non lethal action potentials or calcium variations. Typical biological responses are presented in Figure 3.
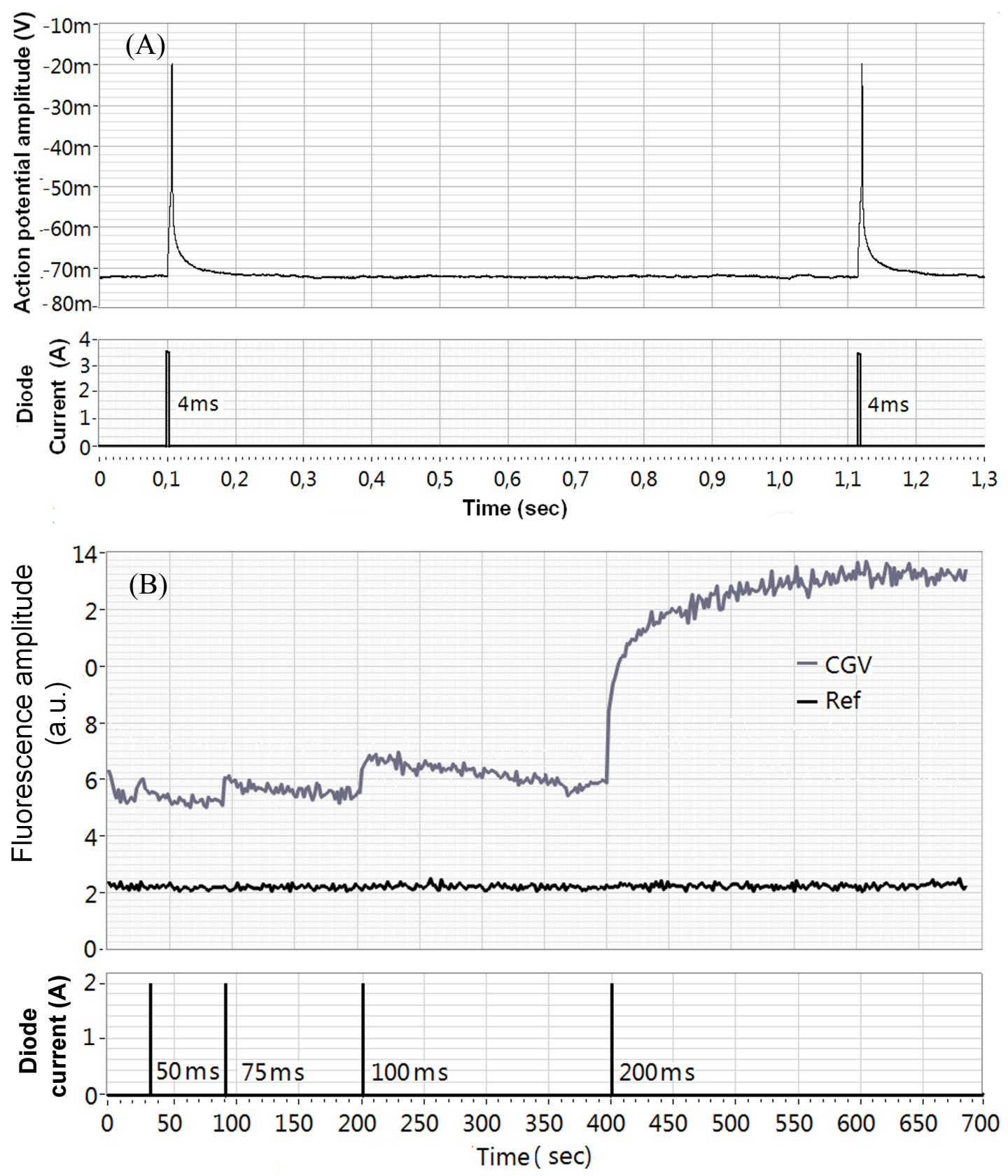

Figure 3. Typical successful laser stimulations (1875 nm). (A) Action potentials evoked by a 4 ms laser single pulse.

(B) Fluorescence amplitude showing intracellular calcium variations of CGV stimulated by laser single pulses with different pulse durations. 


\subsection{Stimulation thresholds}

As shown in Figure 3B, the calcium variation amplitude depends on the stimulation energy. From an energy level upper the energy threshold, the fluorescence amplitude increases as the pulse duration increases (at constant power). The calcium concentration comes back to the equilibrium after a few hundred of seconds. If a permanent saturation of the intracellular calcium is obtained, a swelling of the cell is also visually observed attesting of neuron damages. A similar energy threshold is also required to induce an action potential in the patch-clamp configuration. A lost of a stabilized resting potential after spikes observed for pulse durations (or powers) with values upper the stimulation threshold is accompanied of the swelling of the cell attesting of neuron damages.

\subsection{Effect of the wavelength on energy thresholds}

We have successfully stimulated RGC and VGC by a laser beam at $1470 \mathrm{~nm}, 1535 \mathrm{~nm}$ and $1875 \mathrm{~nm}$ for various pulse durations and powers. RGC and VGC follow a similar stimulation threshold trend. For clarity, only stimulation thresholds measured on VGC are displayed in Figure 4. The optical power at the fiber output function of the pulse duration is plotted for three wavelengths in Figure 4A. Radiant exposure thresholds at the cell surface deduced from the power threshold and the position of the fiber tip are shown in Figure 4B. In this calculation, the Gaussian characteristic of the laser beam at the optical fiber output and the specificity of both measurement methods (fiber insertion angle, cell position in the laser spot, distance between the fiber and cells, water absorption coefficient for each wavelength) was taken into account to estimate the accurate energy received by the cells for both measurement configurations.
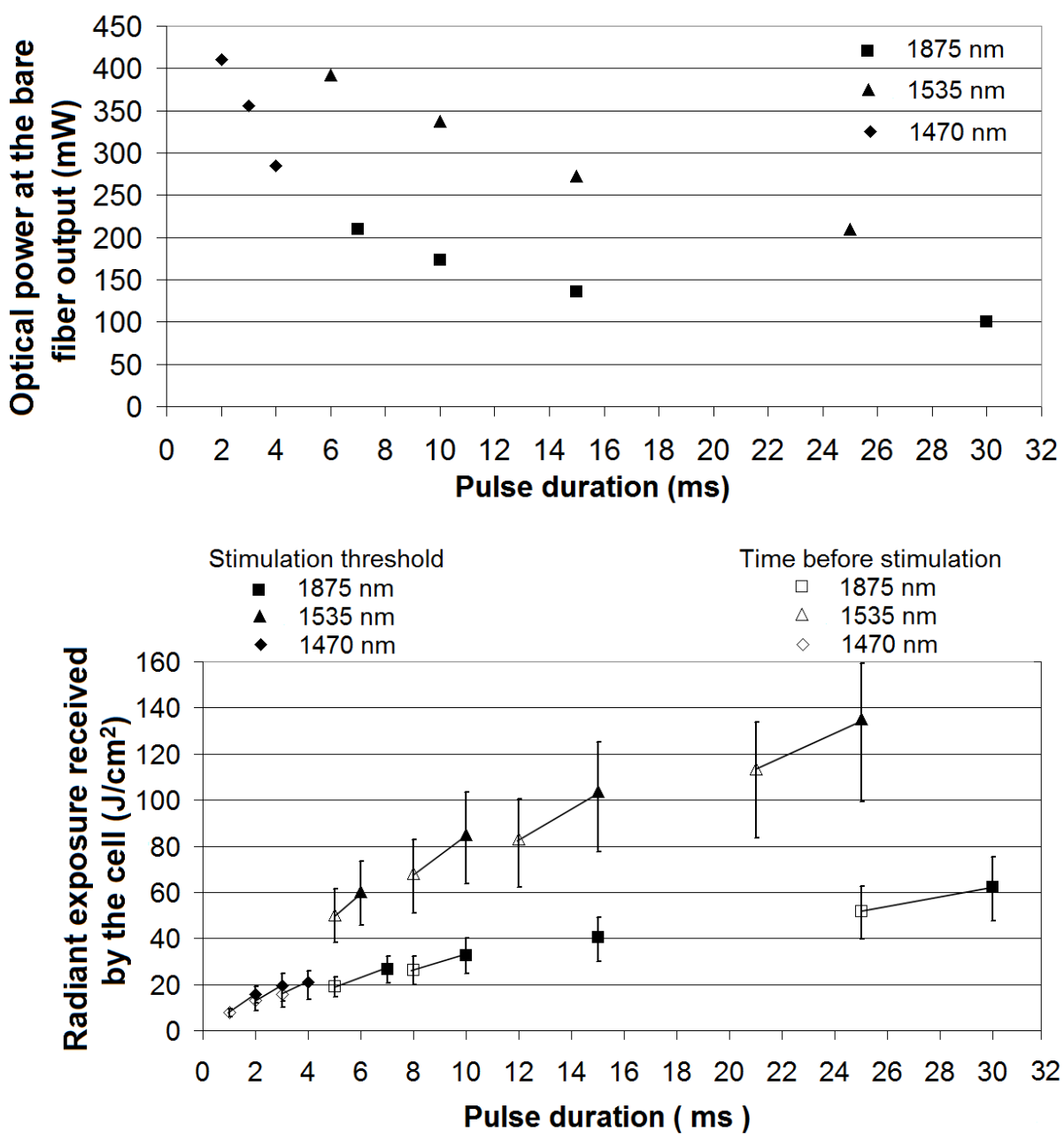

Figure 4. Comparison of the stimulation thresholds for VGC illuminated by a laser beam at $1470 \mathrm{~nm}, 1535 \mathrm{~nm}$ and 1875 $\mathrm{nm}$ and measured by the patch clamp technique. Radiant exposure received by the cells. Uncertainty bars take into account uncertainties on the position of the fiber tip and on the pulse duration. 
Blank marks for the lower pulse durations correspond to the pulse duration tested just before obtaining a biological response. Vertical uncertainty bars have been determined from the uncertainty of the position of the fiber tip relative to the cell for each configuration.

\subsection{Biological neural network effect}

We have observed the spatial selectivity of the laser beam by analyzing the fluorescence imaging variations on neighbored cells (Figure 5). Neighbored VGC of cell 1 are not in the direct path of the laser beam and are not stimulated at first. Biological responses are then observed after a few tens of seconds on these physically interconnected neurons, a typical phenomenon of a biological neural network.
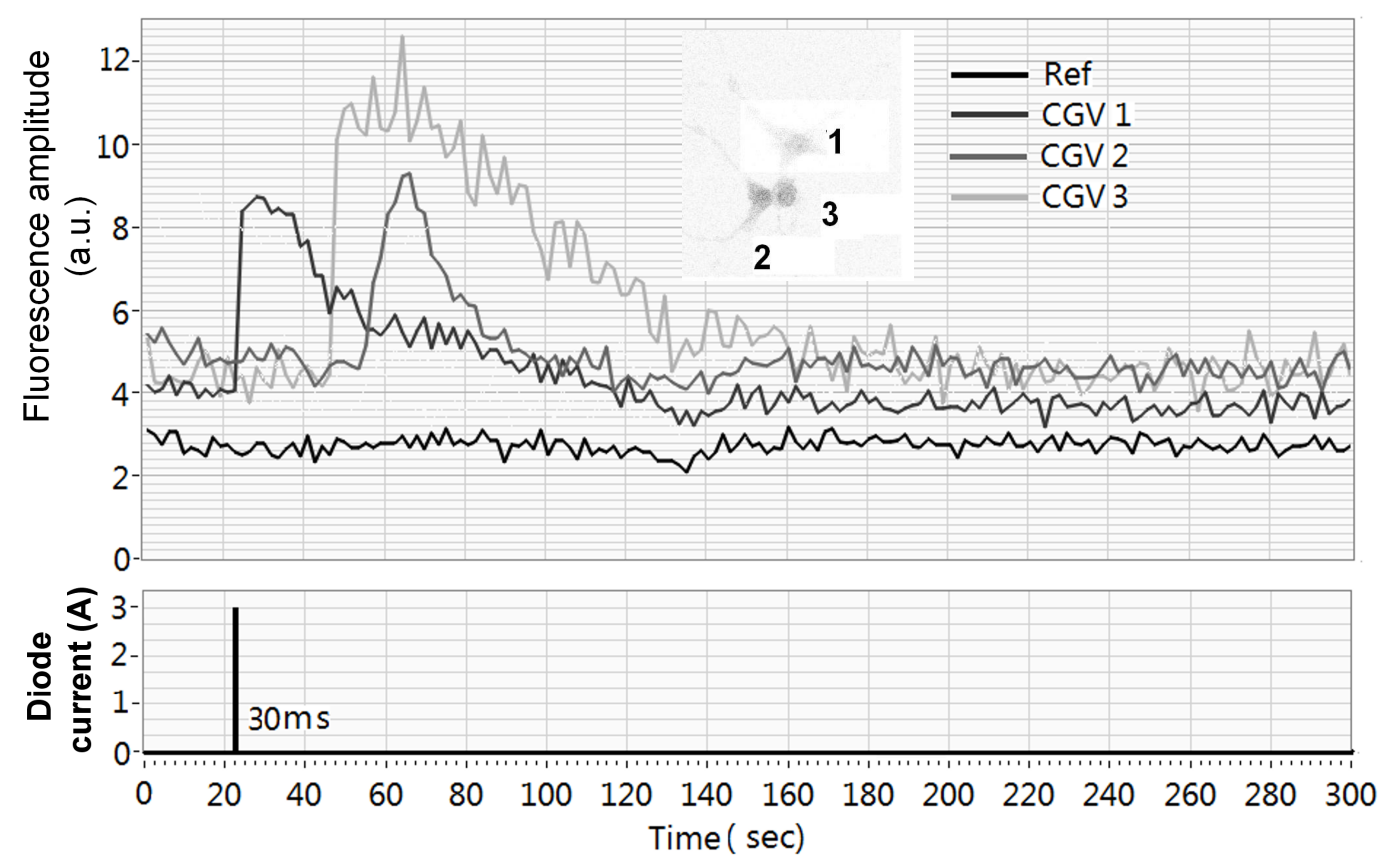

Figure 5. Fluorescence amplitude showing intracellular calcium variations of VGC induced by a $30 \mathrm{~ms}$ laser single pulse. Surrounding VGC of cell 1 are not in the direct path of the laser beam and are not stimulated at first. Network biological responses are then observed on these cells.

\section{DISCUSSION AND CONCLUSION}

Non-lethal and reproducible vestibular and retinal ganglion neuron laser stimulations by single pulses from mid-infrared laser were demonstrated.

As observed in Figure 4, the energy required to stimulate the neurons increases whereas increasing the pulse duration. Several authors have already reported similar results $[1,2]$. The infrared laser energy is strongly absorbed by the water molecules and converted to heat which is localized closely to the fiber tip. Due to the diffusion phenomenon, the heat is no longer completely confined for long pulses. As described by Izzo et al. [2], a constant energy density threshold is found with pulses below $100 \mu$ s. Since lasers and the current source we used were limited in power, we were not able to stimulate neurons below $2 \mathrm{~ms}$.

The absorption coefficient has a major role on the energy threshold as shown in Figure 4B. Lasers at $1535 \mathrm{~nm}$ and at $1470 \mathrm{~nm}$ have the same maximum optical power (around $400 \mathrm{~mW}$ ) but the radiant exposure threshold is clearly higher at $1535 \mathrm{~nm}$ than at $1470 \mathrm{~nm}$. It can be explained by the difference of their water absorption coefficient: $15 \mathrm{~cm}^{-1}$ at $1535 \mathrm{~nm}$ and $30 \mathrm{~cm}^{-1}$ at $1470 \mathrm{~nm}$. As the beam is less absorbed at $1535 \mathrm{~nm}$, it requires more energy to stimulate the neuron. The 
same effect is observed by comparing thresholds and pulse durations at $1875 \mathrm{~nm}$ and $1470 \mathrm{~nm}$. For these wavelengths, the absorption coefficient is similar $\left(30 \mathrm{~cm}^{-1}\right)$ but the laser at $1875 \mathrm{~nm}$ has almost half the maximum power of the laser at $1470 \mathrm{~nm}$. Radiant exposure thresholds of both lasers clearly follow the same trend, giving data expected if the $1875 \mathrm{~nm}$ laser had more power: a decrease of the energy threshold as the pulse duration decreases.

The infrared laser beam is strongly absorbed by water molecules inducing an increase of temperature at the cell membrane illuminated by the laser beam. From calibrations presented in Figure 2, we have measured the temperature increase at the pipette tip in the open pipette configuration by positioning the tip in a position similar to the one with a cell. Figure 6 shows the temperature rise for various pulse durations at maximum and constant optical power for the three wavelengths $(230,410$ and $430 \mathrm{~mW}$, for the 1875,1535 and $1470 \mathrm{~nm}$ lasers, respectively). Results show identical temperature variations at $1875 \mathrm{~nm}$ and at $1535 \mathrm{~nm}$ while at $1470 \mathrm{~nm}$ higher temperatures are reached. In addition, as shown in Figure 4B, pulse durations requiring a stimulation at the maximum optical power are around $6 \mathrm{~ms}$ for 1875 and $1535 \mathrm{~nm}$ lasers and around $2 \mathrm{~ms}$ for the $1740 \mathrm{~nm}$ laser. We can observe in Figure 6 that these three different pulse durations (or energy thresholds) correspond to an almost similar temperature rise from $25^{\circ} \mathrm{C}$ to $55-60^{\circ} \mathrm{C}$ (see dashed line). Specific heat-sensitive ion channels have been identified on various neurons [7]. The temperature threshold we have measured could possibly activate these channels. Immunocytochemical and pharmacological investigations will be the next step to validate their involvement in the laser stimulation of CGV and CGR.

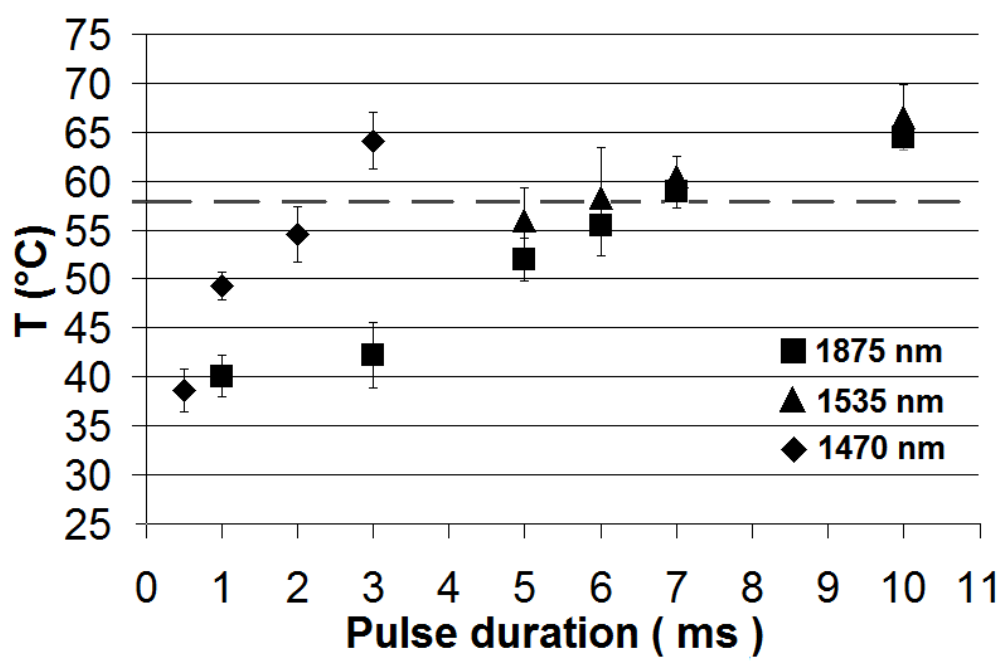

Figure 6. Temperature rise for various pulse durations at maximum and constant optical power for three laser wavelengths.

In summary, we have demonstrated that infrared laser radiations provide a possible way for stimulating retinal and vestibular ganglion cells. Physical characteristics allowing safe and reproducible neuron stimulation by single infrared pulses have been described. Variations of the stimulation energy thresholds from three laser wavelengths suggest that the main physical parameter is the water optical absorption. The estimated temperature at the cell membrane shows that a constant temperature rise is required to stimulate neurons independently of variable energy thresholds. It also suggests that the mechanism of the infrared laser stimulation of retinal and vestibular neurons is based on temperature-sensitive ion channel stimulation.

\section{ACKNOWLEDGEMENTS}

We are grateful to Dr. Gilles Desmadryl (Institut des Neurosciences de Montpellier), Dr. Yves Rouillard (Institut d'Electronique du Sud) and Guillaume Tatur (Ecole des Mines d'Alès) for technical assistance and to Drs Guy Laeners and Agnès Muller (Institut des Neurosciences de Montpellier) for helpful comments.

This research was supported by the European Aeronautic Defence and Space corporate foundation. 


\section{REFERENCES}

[1] Wells, J., Kao, C., Konrad, P., Milner, T., Kim, J., Mahadevan-Jansen, A. and Jansen, E. Duco, "Biophysical mechanisms of transient optical stimulation of peripheral nerve," Biophys. J. 93(7),2567-2580 (2007).

[2] Izzo, A. D., Walsh, J. T., Ralph, H., Webb, J., Bendett, M., Wells, J. and Richter C-P. "Laser stimulation of auditory neurons: effect of shorter pulse duration and penetration depth," Biophys. J. 94(8),3159-3166 (2008).

[3] Yao, J., Liu, B. and F. Qin, "Rapid temperature jump by infrared diode laser irradiation for patch-clamp studies, " Biophys. J. 96,3611-3619 (2009).

[4] Liang, S., Yang, F., Zhou, C., Wang, Y., Li, S., Sun, C.K., Puglisi, J.L., Bers, D., Sun, C. and Zheng J. "Temperature-dependent activation of neurons by continuous near-infrared laser," Cell Biochem. Biophys. 53(1),33-42 (2009).

[5] Dayanithi, G., Desmadryl, G., Travo, C., Chabbert, C. and Sans, S. "Trimetazidine modulates AMPA/kainate receptors in rat vestibular ganglion neurons," Eur. J. Pharmacol. 574(1), 8-14 (2007).

[6] Cesare, P., Moriondo, A., Vellani, V. and McNaughton P. A. "Ion channels gated by heat," Proc. Natl. Acad. Sci. USA, Irvine 96(14),7658-7663 (1999).

[7] Dhaka, A., Viswanath, V. and Patapoutian, A. "Trp ion channels and temperature sensation," Annu. Rev. Neurosci. 29,135-161 (2006). 